[Short Communication]

\section{A new species of the genus Takayus (Araneae: Theridiidae) from Nagano Prefecture, Central Japan}

\author{
Hajime Yoshida \\ 7-16, Kagota 2 Chome, Yamagata-shi, \\ Yamagata, 990-2484 Japan \\ E-mail: araneae@mb.infoweb.ne.jp
}

\begin{abstract}
A new species of the family Theridiidae is described from Nagano Prefecture, Central Japan, under the name, Takayus fujisawai.
\end{abstract}

Key words - Takayus, Theridiidae, new species, Nagano Prefecture, Japan

In my previous paper (Yoshida 2001), I described a new genus, Takayus, and newly transferred six Japanese and ten Chinese species to it. Recently, Mr. Yosuke Fujisawa, Nagano, collected an unknown species of the genus Takayus from high altitudinal region of Nagano Prefecture, Japan. A literature search revealed that it is a new species as described below.

\section{Takayus Yoshida 2001 \\ [Japanese name: Takayu-himegumo zoku]}

Takayus Yoshida 2001, p. 165 (Type species: Theridion takayense S. Saito 1939).

Takayus fujisawai new species [Japanese name: Fujisawa-himegumo]

(Figs. 1-7)

Diagnosis. This species resembles Takayus quadrimaculatus (Song \& Kim 1991), T. lushanensis (Zhu 1998) and T. xui (Zhu 1998) described from China (cf. Zhu 1998, pp. $178^{-182}$, figs. 114-116), but is distinguished from them by epigynum with a wide scapus (Fig. 4), seminal receptacles each with a posterior projection (Fig. 5) and male palpus with a large tegular apophysis (Figs. 6-7).

Description. Carapace oval, eye region slightly elevating and a clypeus anteriorly projecting. First patella and tibia nearly twice as long as carapace length. Leg formula, $1,4,2,3$ in female, $1,2,4,3$ in male. Abdomen spherical, slightly longer than wide and high (Figs. 1-3).

Female genitalia as shown in Figs. 4-5: epigynum with a small and wide scapus; openings situated under the scapus; each of seminal receptacles oval with a posterior projection, far from the openings; duct long and twisted.

Male palpus as shown in Figs. 6-7: embolus thick and long with a large base and pointed tip; tegular apophysis large, prolaterally projecting.

Coloration (Figs. 1-3). Carapace brown medially with a dark fleck. Chelicerae, maxillae, labium and sternum brown. Legs brown: femora and patellae respectively distally with a blackish band; tibiae and metatarsi respectively with a basal and a distal blackish bands. Bands of third and fourth legs indistinct. Abdomen whitish brown, dorsally with dark brown flecks; spinnerets surrounded with one large ventral and two small dorsal black spots. Scapus of epigynum blackish brown (Fig. 4).

Measurements (in $\mathrm{mm}$, 우 holotype/ $\nsim$ allotype). Body length 4.13/2.37. Carapace length 1.45/1.11; width 1.29/0.88. Abdomen length 2.84/1.45; width 2.95/1.03; height 2.79/1.05. First leg: femur 2.84/2.37; patella and tibia 2.84/2.63; metatarsus 2.37/2.47; tarsus $0.82 / 0.79$. Second patella and tibia 1.79/1.66; third patella and tibia 1.21/0.97; fourth patella and tibia 2.00/1.53. Diameters: anterior median eye $0.11 / 0.08$; anterior lateral eye $0.11 / 0.08$; posterior median eye $0.11 / 0.08$; posterior lateral eye $0.11 / 0.08$. Distances: between anterior median eyes $0.13 / 0.11$; between anterior median and lateral eyes $0.04 / 0.05$; between posterior median eyes $0.11 / 0.11$; between posterior median and lateral eyes $0.11 / 0.08$. Median ocular area, anterior width $0.29 / 0.24$; posterior width $0.29 / 0.24$; length $0.26 / 0.21$.

Variation. Female paratype: body length $3.95 \mathrm{~mm}$; carapace length $1.42 \mathrm{~mm}$; abdomen length $2.53 \mathrm{~mm}$.

Type series. Holotype 우, allotype ${ }^{\top}$, and 1 우 paratype, Yamada Farm 1,750 m alt., Takayama-mura, Kami-takai-gun, Nagano Prefecture, Japan, 8-VII-2002, Yosuke Fujisawa leg. (Araneae Collection of the Department of Zoology, National Science Museum, Tokyo, 5271-5273).

Collecting note (Fujisawa pers. comm.). The collecting point is a ridge about $1,750 \mathrm{~m}$ alt., and the present new species was not found below there. It built a web on a fir tree, Abies homolepis Sieb. \& Zucc. (Figs. 1-2). Takayus takayensis (S. Saito 1939) was seen below 1,600 m alt. instead of the present new species.

Distribution. Japan: Honshu (Nagano Prefecture).

Etymology. The specific name is dedicated to $\mathrm{Mr}$. Yosuke Fujisawa, Nagano, who collected the type specimens.

\section{Acknowledgments}

I wish to express my sincere thanks to Mr. Yosuke Fujisawa, Nagano, for offering specimens and photographs of the new species used in this paper.

\section{References}

Saito, S. 1939. On the spiders from Tôhoku (northern most part of the main island), Japan. Saito Ho-on Kai Mus. Res. Bull., 18: 1-91, pl. 1.

Song, D. \& Kim, P. 1991. On some species of spiders from Mount West Tianmu, Zhejiang, China (Araneae). Korean Arachnol., 7 (1): 

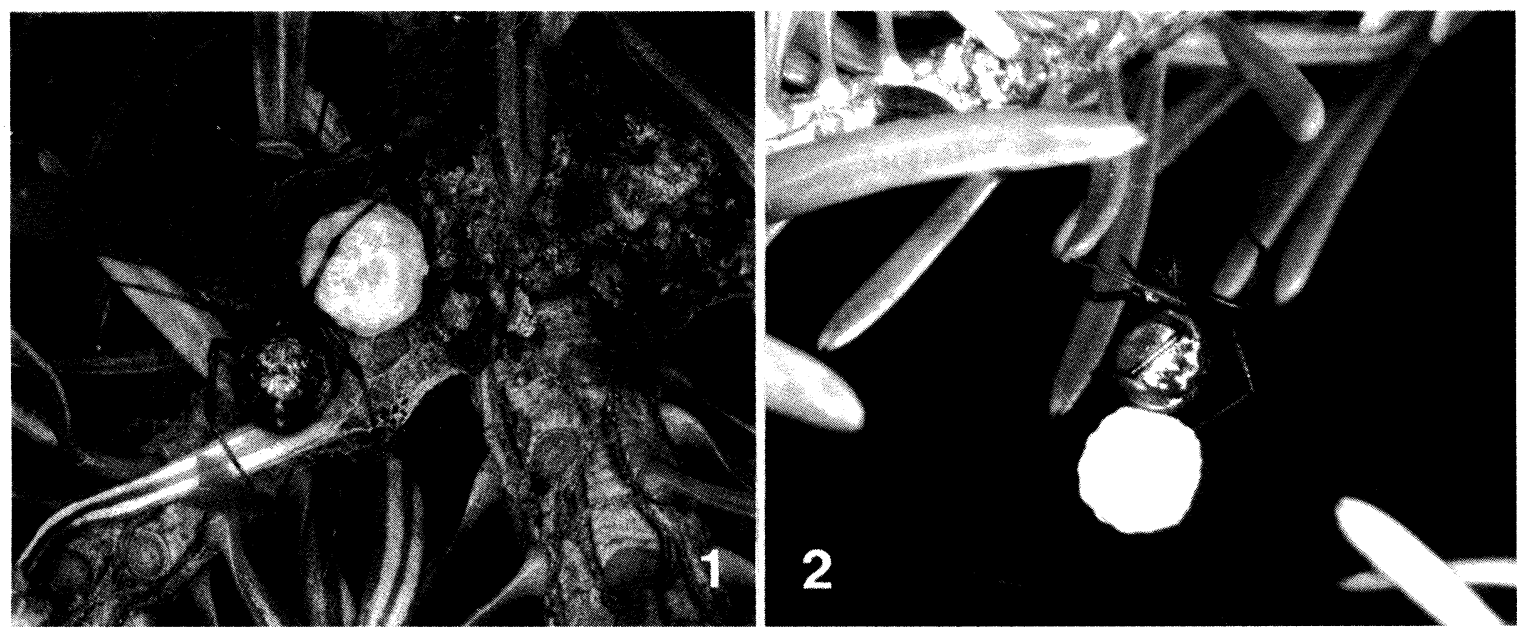

Figs. 1-2. Takayus fujisawai new species, female with an egg sac in a web built on Abies homolepis Sieb. \& Zucc., Takayamamura, Nagano Pref., 8-VII-2002. [Photo: Y. Fujisawa]

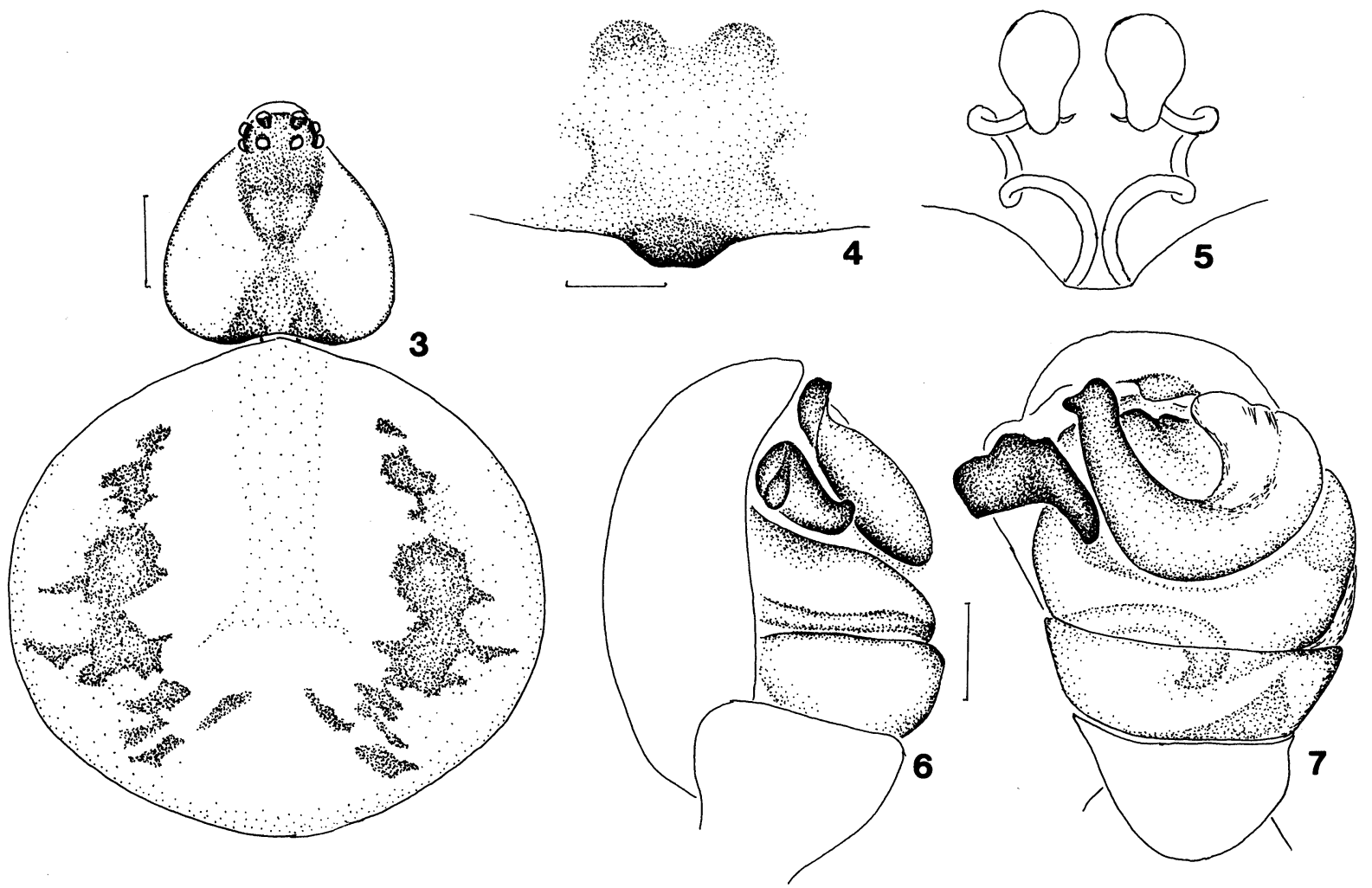

Figs. 3-7. Takayus fujisawai new species, ㅇ holotype and $\delta^{\Uparrow}$ allotype -3 , female carapace and abdomen, dorsal view; 4, epigynum, ventral view; 5 , female internal genitalia, dorsal view; 6-7, male left palpus, prolateral (6) and ventral (7) view. Scales: $0.5 \mathrm{~mm} \mathrm{(3)} \mathrm{and} 0.1 \mathrm{~mm}(4-7)$.

19-27.

Yoshida, H. 2001. A revision of the Japanese genera and species of the subfamily Theridiinae (Araneae: Theridiidae). Acta Arachnol., 50: $157-181$.

Zhu, M. 1998. Fauna Sinica, Arachnida, Araneae, Theridiidae.
Science Press, Beijing. ix +436 pp., 1 pl. (In Chinese with English summary)

Received September 24, 2002 / Accepted October 5, 2002 
従来ヒメアシダカグモに使用されていた Sinopoda stellata （Schenkel 1963）を日本のクモから削除した．同種は中国内陸 部に固有の種と考えられる。

スマトラ島のカブリダニ類（ダニ目：カブリダニ科）（pp. 125133

江原昭三（勇680-0001 鳥取市浜坂 2丁目 15-7）（pp. 125-133）

高藤晃雄氏（京都大学）が 1981 年 12 月にインドネシアのス マトラ島で種々の植物から採集した標本が，この研究に用いら れた. 12 種のカブリダニが同定され，この中の 1 種は新種で, Amblyseius (A.) sumatrensis として記載された。他の 11 種はす べてスマトラからの新記録種である。これらのうち, 従来あま りょく知られていない Amblyseius (Neoseiulus) circellatus Wu \& Li 1983, および Paraphytoseius seychellensis Schicha \& CorpuzRaros 1985 については, 再記載が与えられた。前者の雄はこの たび初めて記載された，残りの種の大部分については，主要な 識別形質が記述された.

中国地方産のモリヒメグモ属（クモ目：ヒメグモ科）の 3 種 (pp. 135-137)

吉田 哉 (下990-2484 山形市篭田 2丁目 7 番 16 号)

中国地方からモリヒメグモ属 Robertus の 3 種を記録した。 そのうちの 1 種, ノジマモリヒメグモ（新称） R. nojimai, を 新種として記載した。その他の 2 種, キタモリヒメグモ $R$. sibiricus Eskov 1987 抢よびサイトウモリヒメグモ R. saitoi Yoshida 1995，を岡山県および鳥取県から初めて記録した。 キ タモリヒメグモは本州新記録となる。
長野県産のタカユヒメグモ属（クモ目：ヒメグモ科）の 1 新種 (pp. 139-140)

吉田 哉（广990-2484 山形市篭田 2丁目 7 番 16 号）

長野県産のヒメグモ科タカユヒメグモ属 Takayus の 1 新種を フジサワヒメグモ（新称）T. fujisawai の名前で記載した. 高 山村山田牧場の上部標高 $1,750 \mathrm{~m}$ ほどの尾根部分で, ウラジロ モミ（ダケモミ）Abies homolepis Sieb. \& Zucc.に網を張ってい るところを採集された。

南西諸島産のユウレイグモ属およびシモングモ属（クモ目，ユ ウレイグモ科) の 2 新種 (pp. 141-144)

入江照雄（下860-0082 熊本市池田 2 丁目 19-11）

南西諸島産のユウレイグモ科の 2 新種, Pholcus okinawaensis オキナワユウレイグモ(新称, 沖縄島産, 与論島産)打よび Spermophora yanbaruensis ヤンバルユウレイグモ（新称, 沖縄 島産）を記載した。

日本初記録のソルホイオニダニ（ササラダニ亜目 : オニダニ科） (pp. 145-147)

島野智之 ${ }^{1}$, 坂田知世 ${ }^{2}$, Roy A. Norton ${ }^{2}$ ('T960-2156 福島市荒 井字原宿南 50 東北農業研究センター烟地利用部 畑土壌管 理研究室; ${ }^{2}$ College of Environmental Science and Forestry, State University of New York, USA)

Camisia solhoeyi Colloff（ソルホイオニダニ, 新称）を初めて 日本から記録した，本種は，胴背毛 $\mathrm{h} 1$ が他の胴背毛よりあ短 いという特徴によって日本に生息する他の近縁な種と区別でき る. よく知られている C. lapponica (Trägårdh) は, 本種と非常 によく似て抢り, 以前の C. lapponica の日本での記録は, 再調 查される必要があるかも知れない. 